\title{
Chronic deflation in Japan ${ }^{1}$
}

Kenji Nishizaki, Toshitaka Sekine, Yuichi Ueno and Yuko Kawai ${ }^{2}$

\begin{abstract}
This short paper is an abbreviated version of Nishizaki et al (2012). Japan has suffered from long-lasting but mild deflation since the latter half of the 1990s. Estimates of a standard Phillips curve indicate that a decline in inflation expectations, the negative output gap, and other factors such as a decline in import prices and a higher exchange rate, all account for some of this development. These factors, in turn, reflect various underlying structural features of the economy. This paper examines a long list of these structural features that may explain Japan's chronic deflation.
\end{abstract}

Keywords: deflation, Japan

JEL classifications: E31, E58, O53

1 This short paper is an abbreviated version of Nishizaki et al (2012). Please see Nishizaki et al (2012) for further discussion.

2 Bank of Japan. 


\section{Introduction}

Why have price developments in Japan been so weak for so long? What can current economics tell us about the possible causes for these developments? Despite the obvious importance of the practical and academic implications and somewhat to our surprise, few serious academic attempts had been made to research these questions. To shed light on these issues, the Bank of Japan's Research and Statistics Department and the Center for Advanced Research in Finance (CARF) of the University of Tokyo invited prominent Japanese economists to a joint conference on 24 November 2011. This short paper seeks to document the event's main findings, together with our interpretation. We first summarise certain data sets to outline the development of deflation in Japan. Then, we list and examine the hypotheses discussed in the above-mentioned conference. In the concluding section, we provide our own thinking as to the most prominent variables and lessons to be learned from our experience.

\section{Deflation in Japan}

Figure 1 shows the major inflation indicators for Japan. Both of them show that Japan has faced declining prices since the mid-1990s. The CPI less fresh food first turned negative in or around 1995 and, since 1998, it has remained almost always slightly negative, except for the period of the commodity price surge before the global financial crisis. The GDP deflator declined more rapidly since the middle of the 1990s. In this paper, we call this post-mid-1990s period of deflation the "chronic deflation".

The charts in Figure 2 compare price developments in G3 economies. All of them show that Japan's price increases have historically been weaker, even before the Chronic Deflation era. Japan's headline inflation had usually been two to three percentage points lower than in the United States and the euro area. A decomposed analysis into goods and services prices inflation tells the same story. Other nominal variables, such as nominal ULC and nominal interest rate, are also weaker in Japan than in the United States and the euro area.

These data indicate that Japan has, in a genuine sense, experienced a mild but long-lasting deflation: that is, all nominal values have been weak. Also the international comparison may suggest that there is a structural cause for Japan to be deflationary.

\section{Possible causes}

At the conference, several variables were suggested as responsible for the prolonged deflation. To begin with, we estimated a New Keynesian Phillips curve to confirm the basic data (Table 1). The CPI increased by about $1.5 \%$ up to the middle of the $1990 \mathrm{~s}$, but after that it became zero or negative. Trend inflation, which is a proxy for long-run inflation used to push up the inflation rate by more than one percentage point, but the effect diminished after that point. The output gap has continued to push down the inflation rate since the middle of the decade. And other factors, which include the effects of all other off-model variables such as the impact of exchange rates or the change in margins, have also helped to push down the inflation rate by a slightly larger degree since 2000 .

From this exercise, we conclude that we cannot single out any prime suspect as the cause of deflation. In the rest of our paper, we analyse the major candidate variables and the underlying driving factors behind them, and the associated hypotheses suggested in the conference. 


\section{Inflation expectations}

The first candidate is inflation expectations, under which heading we ask "How far have inflation expectations declined?" and "Why have inflation expectations declined?".

Figure 3 shows various measures of expected inflation. They all indicate that long-run inflation expectations had declined but had not fallen into negative territory. Therefore, the answer to the first question is that the expectations for long-run inflation had fallen but did not go below zero. Hence we may tentatively conclude that expectations certainly helped to drag the inflation rate down but not as far as to bring it into the negative regime, ie deflation.

Although long-run inflation expectations remained positive, it might be useful to identify the reasons why inflation expectations declined, as these could be the drivers that led to the deflationary environment. Three hypotheses were discussed at the conference. The first was that the central bank's lowering of the inflation target had the effect of bringing down the public's inflation expectations. The second was that the central bank's inefficient communications strategy sent a deflationary signal to the public. And the third was that the public perceived that Japan's prices were in general too high in comparison with those of other countries. Figure 4 shows relative prices against the US and major trading partners based on the PPP exchange rate. This indicates that Japan's prices were more than 1.8 times higher than those of the United States around the middle of the 1990s. Since then, the price gaps have narrowed as Japan's prices have remained weaker than those of other countries.

\section{The negative output gap}

As Figure 5 showing various measures of the output gap indicates, the output gap in Japan has been largely negative since the 1990s. This is a natural suspect as a cause of deflation, given that oversupply should bring down the price of goods and services. But why should the output gap be negative? Although Japan encountered a series of mishaps at key inflection points, such as the collapse of domestic asset price bubble, the domestic banking and the Asian crisis, the bursting of the dotcom bubble and the global financial crisis, we also have hypotheses that address more fundamental causes.

The first hypothesis is the negative natural rate of interest. At the conference, Watanabe (2012) estimated that the natural rate of interest in Japan, using the technique of Laubach and Williams (2003), fell into negative territory. If this were the case, just as Krugman (1998) argues, Japan may also have fallen into a liquidity trap. In order to cross-check Watanabe's estimate, we gathered various measures of potential growth or long-run growth expectations that should correlate with the natural rate of interest (Figure 6). All of them seem to suggest that potential growth had declined but not into negative territory except for a short period of time. Therefore, this hypothesis is neither proven nor disproved.

The second hypothesis is a negative permanent productivity shock. When potential growth declines, this normally leads to a narrowing of the negative output gap. However, this thought process ignores how the demand side would respond to a shock that delivers a decline in potential growth. If it were due to a temporary shock, demand would not respond that much because of consumption smoothing, and the output gap would improve leading to an increase in the inflation rate. On the other hand, if a decline in the potential growth were delivered by a negative permanent shock in productivity, demand would react more in anticipation of a future decline in income growth, leading to deflation. These hypotheses can be confirmed by the impulse response of a DSGE model (Figure 7). The above panel is a temporary shock where inflation goes up, whereas the bottom panel is a permanent shock. Inflation goes down.

The third hypothesis is risk aversion on the part of banks. If banks become more risk averse for some reason, then they would pile up JGB assets instead of extending loans to private business sectors. This would widen the output gap and lead to lower inflation. This hypothesis can be confirmed by impulse responses of another DSGE model where cautiousness on the part of banks is represented by Adrian-Shin's (2010) type of value-at- 
risk constraint (Figure 8). In the upper panels, a shock to banks' net worth would dampen both output and inflation. Moreover, the DSGE model confirms that if there is negative permanent productivity shock, that shock would tighten the VaR constraint and thus widen the output gap and encourage deflation.

\section{Other factors}

In addition to the above two categories, other off-model factors might be considered. Indeed, several external factors were suggested at the conference.

The first was the exchange rate. The yen's nominal effective exchange rate has tended to appreciate. At the conference, it was suggested that, if there had been a strong expectation for the yen to appreciate, it could have formed a liquidity trap. In other words, if uncovered interest parity holds, the short-term nominal interest rate may be subject to the zero lower bound and the economy may hence fall into a liquidity trap when the yen appreciates.

The second external factor discussed was a supply shock from the emerging economies. In the context of the Great Moderation, some researchers claim that supply shocks of emerging economies are one of the sources. At the conference, a three-country DSGE model showed that a positive productivity shock in China's final goods sector would lower Japan's inflation more than that of the United States (Figure 9).

\section{Conclusion}

As noted above, a number of hypotheses exist as to why Japan has suffered from chronic deflation. At the conference, however, no one factor could be singled out as the primary cause. Table 2 lists the hypotheses raised and we tentatively evaluate the contribution of each candidate variable as follows.

As shown in the estimation results of the New Keynesian Phillips curve, we believe that Japan's chronic deflation is a consequence of multiple causes rather than of a single factor. However, on a detailed view, some factors may have had a stronger effect than others. For example, inflation expectations were generally stable except during the financial crisis of the 1990s. Expectations for the appreciation of the yen in the foreign exchange market were not persistent. By eliminating seemingly weak contributors, we tentatively conclude that we were left with the long-lasting negative output gap.

If such is the case, what measures to prevent prolonged deflation could be suggested from our experience? As many countries may be moving in the same direction as Japan, it might be worthwhile to highlight some lessons that arise from our experience. Behind the widening of the output gap, we identified two major causes - one is the prolonged clean-up process for banks' balance sheets, which is only now being completed 15 years after the bubble burst in the 1990s. This process is closely related to the hypothesis based on banks' risk aversion. The other is the demographic deterioration, which has lowered the natural rate of interest and expectations for future income growth.

The lessons are relatively simple; to avoid impairing bank balance sheets, try to prevent asset bubbles. If, nonetheless, a bubble does blow up, combat it at an early stage. In the long run, make adequate preparations for the ageing of the population.

These conclusions are easy enough to list but rather more difficult to implement, as they require both political action and public assent. However, given that we now have more tools and knowledge to hand than Japan did in the 1990s, we could employ macroprudential policies involving a coordinated approach of both the prudential and macro policy wings, observe cross-border money flows, and use the information and experience to plan effective contingency procedures and promote the construction of a sound social security system. 
All the hypotheses listed in this paper require further examination and research. As involuntary pioneers in this field, we intend to continue investigating the causes of Japan's prolonged deflation and possible countermeasures.

Figure 1

\section{Inflation indicators}

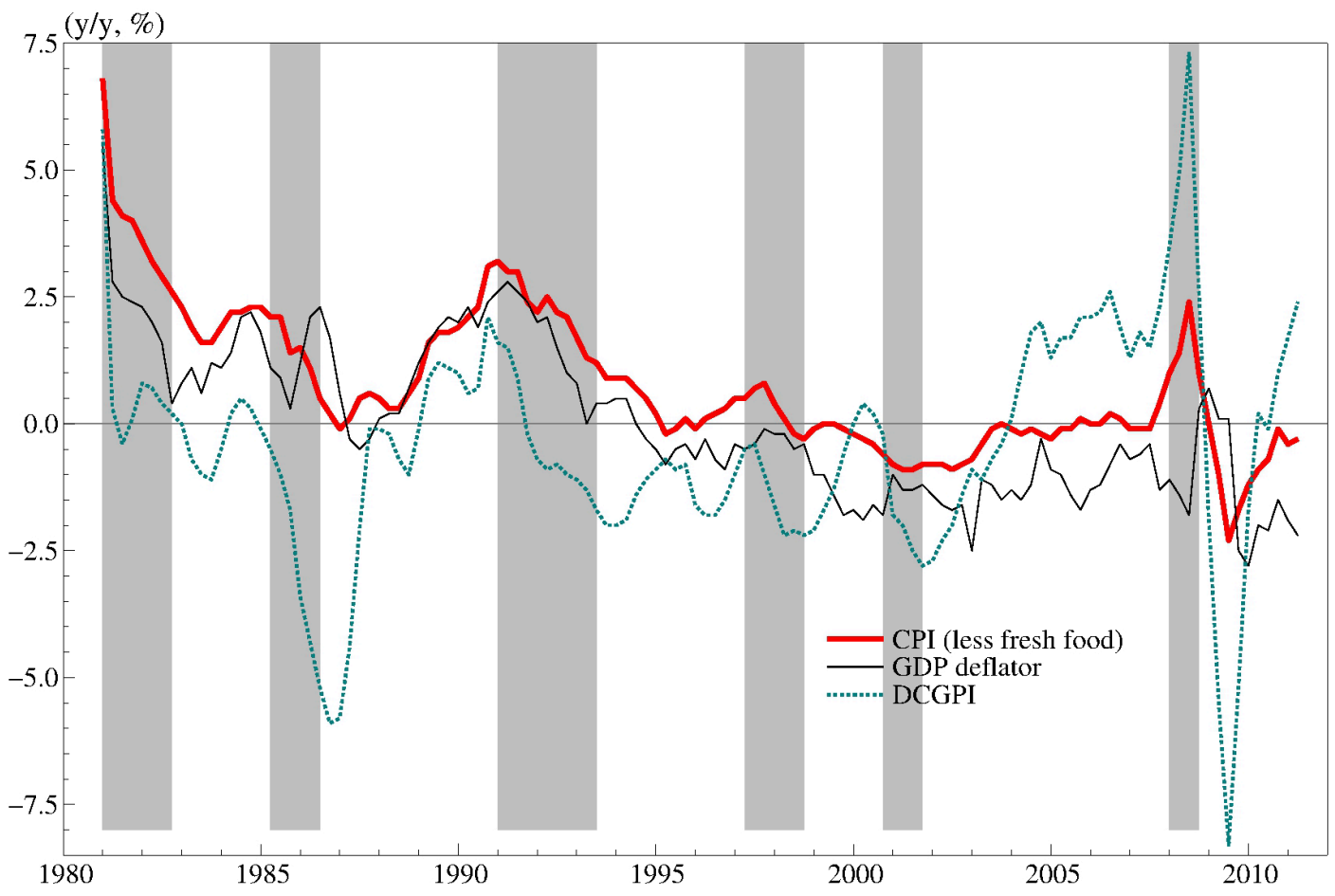

Figure 2

\section{G3 comparison}
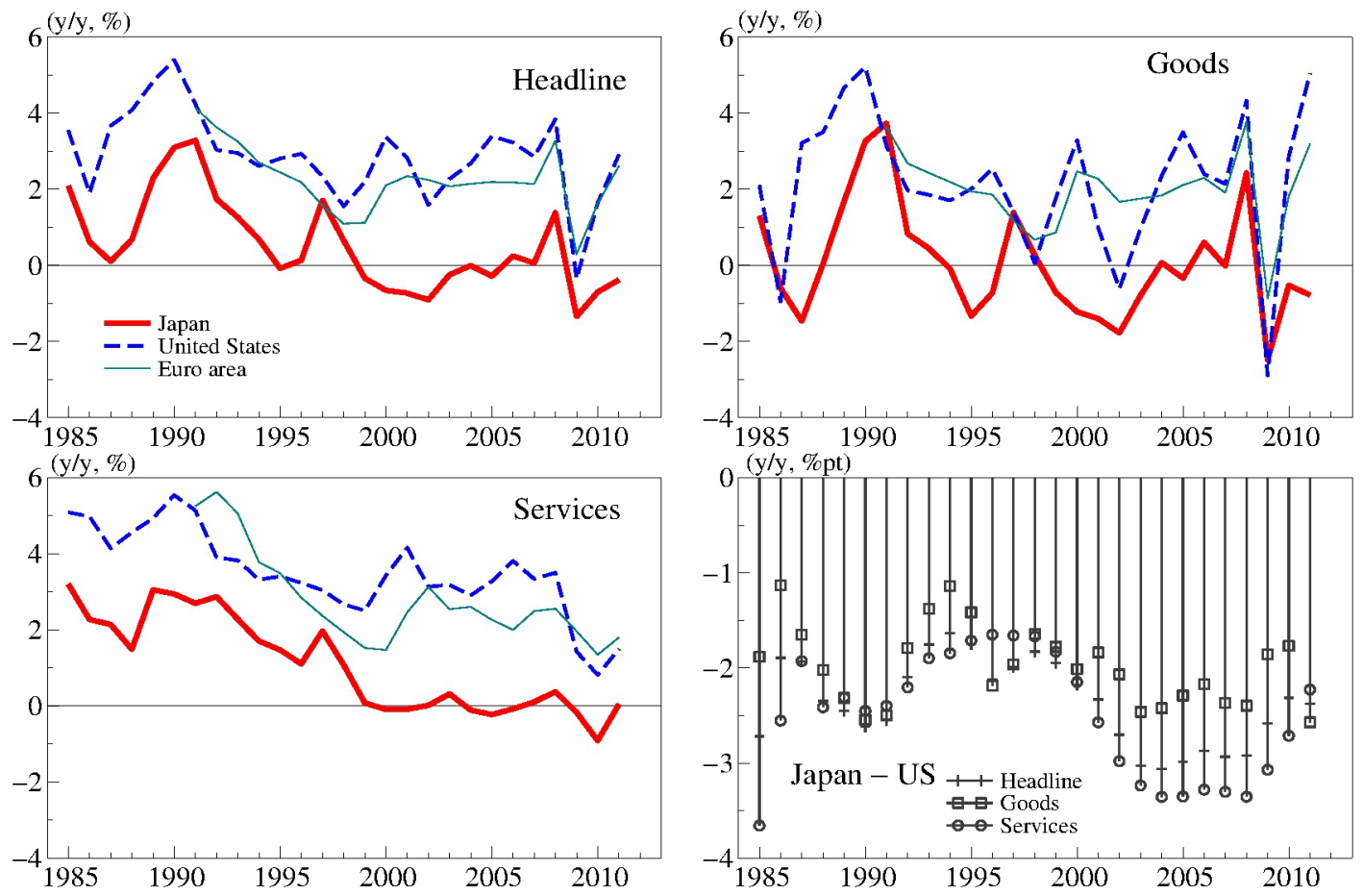
Figure 3

\section{Expected inflation}

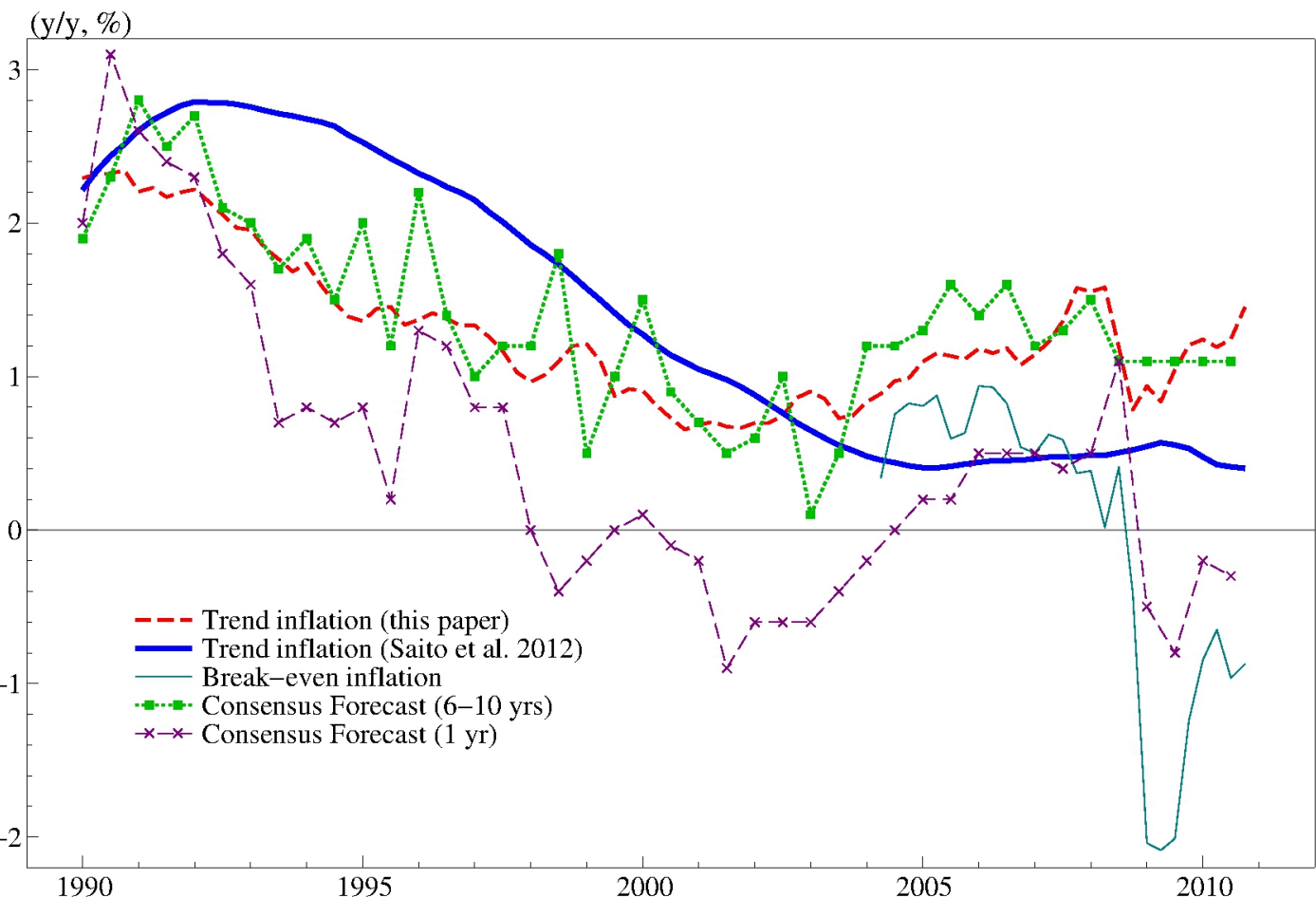

Figure 4

\section{Domestic-foreign price gap}
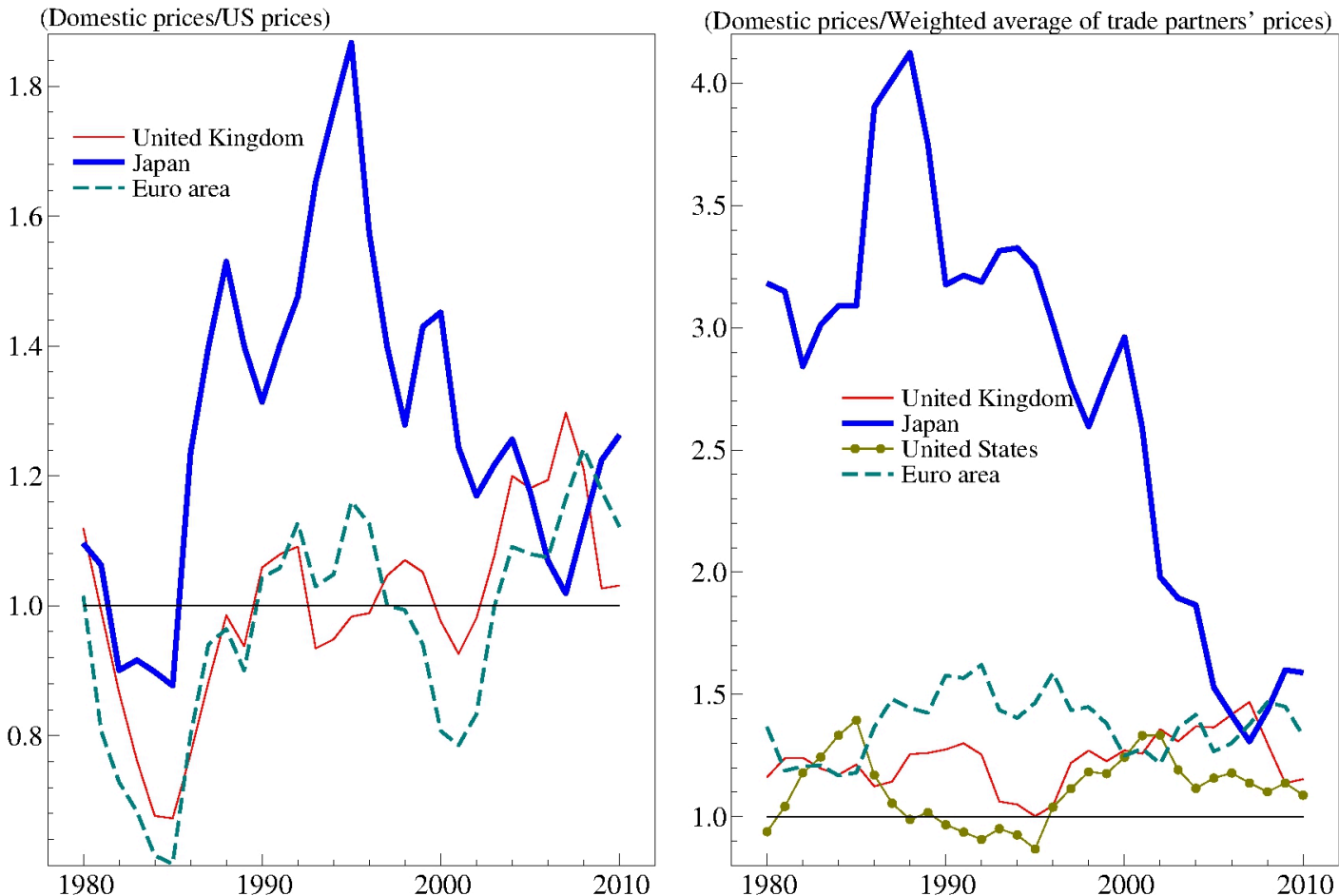
Figure 5

The output gap

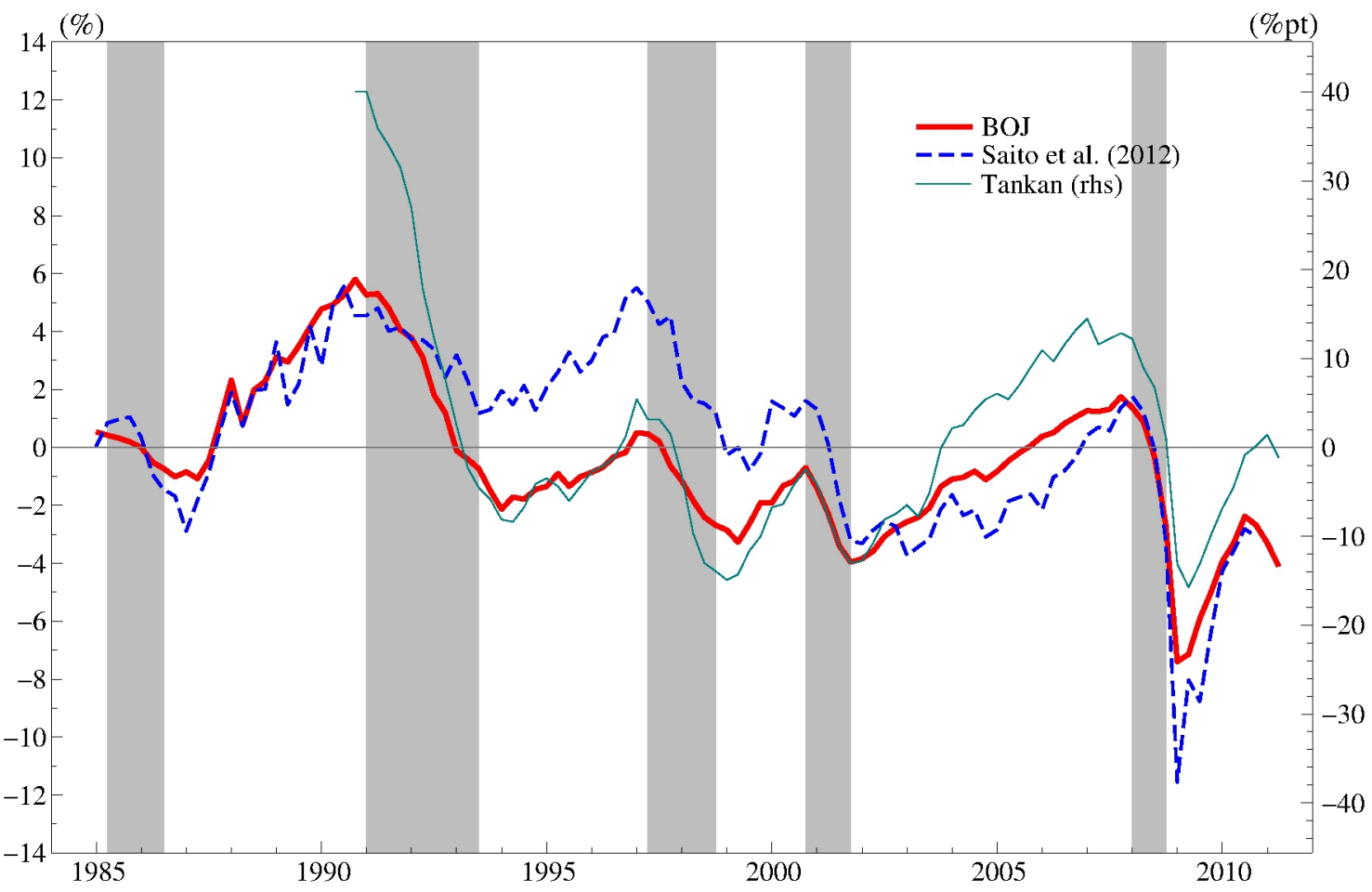

Figure 6

Potential growth

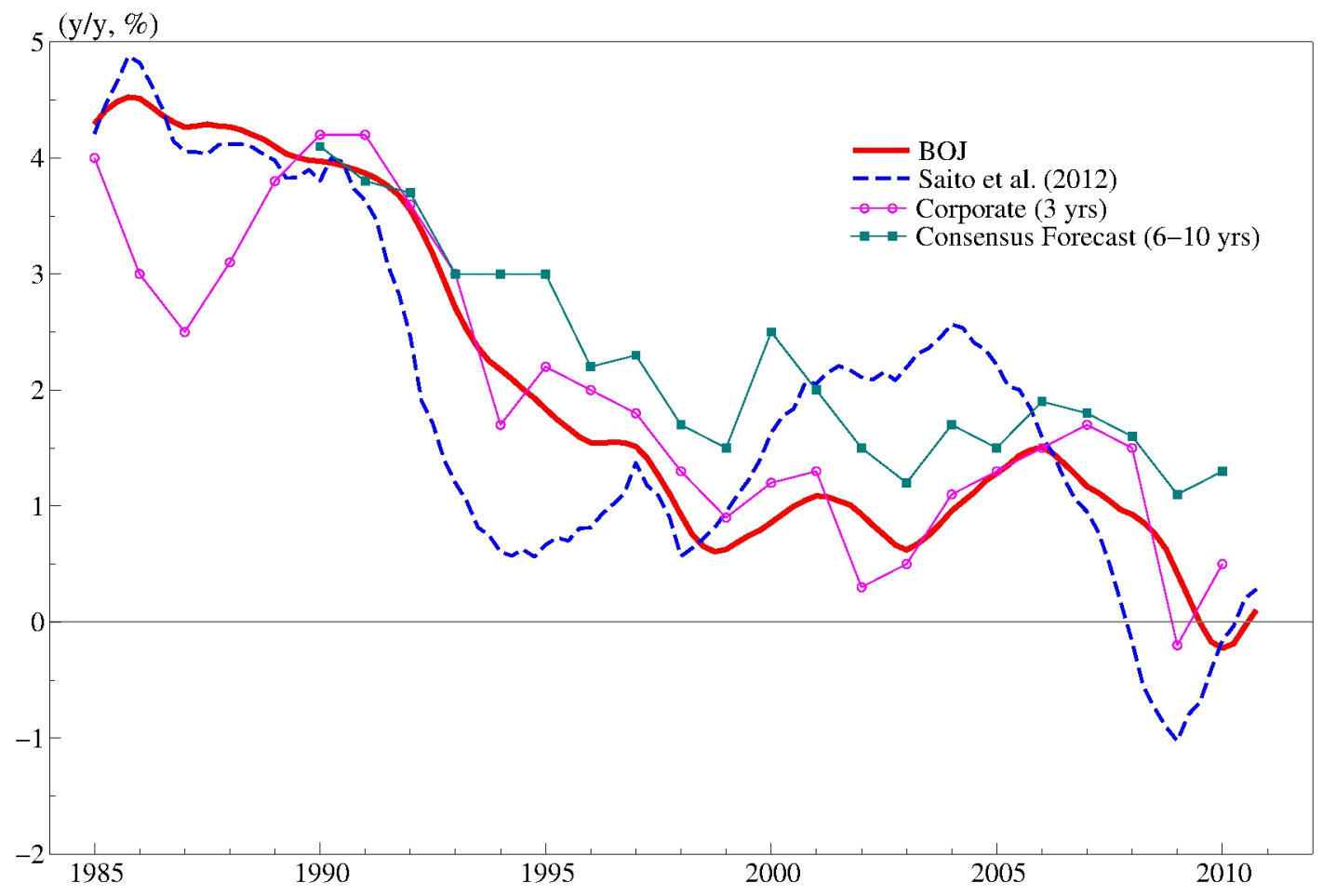


Figure 7

\section{Effect of temporary and permanent productivity shocks}

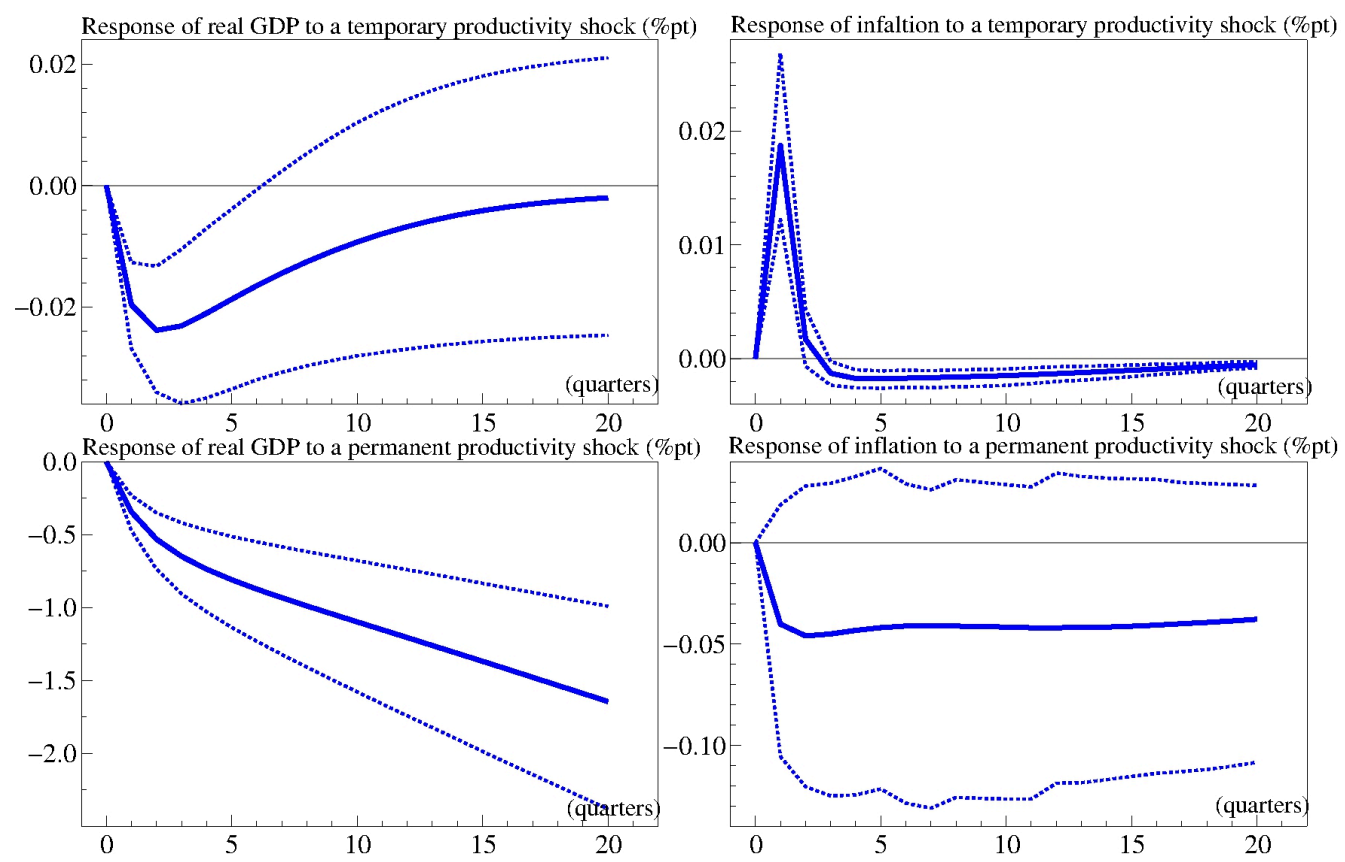

Figure 8

\section{Effect of VaR constraint}
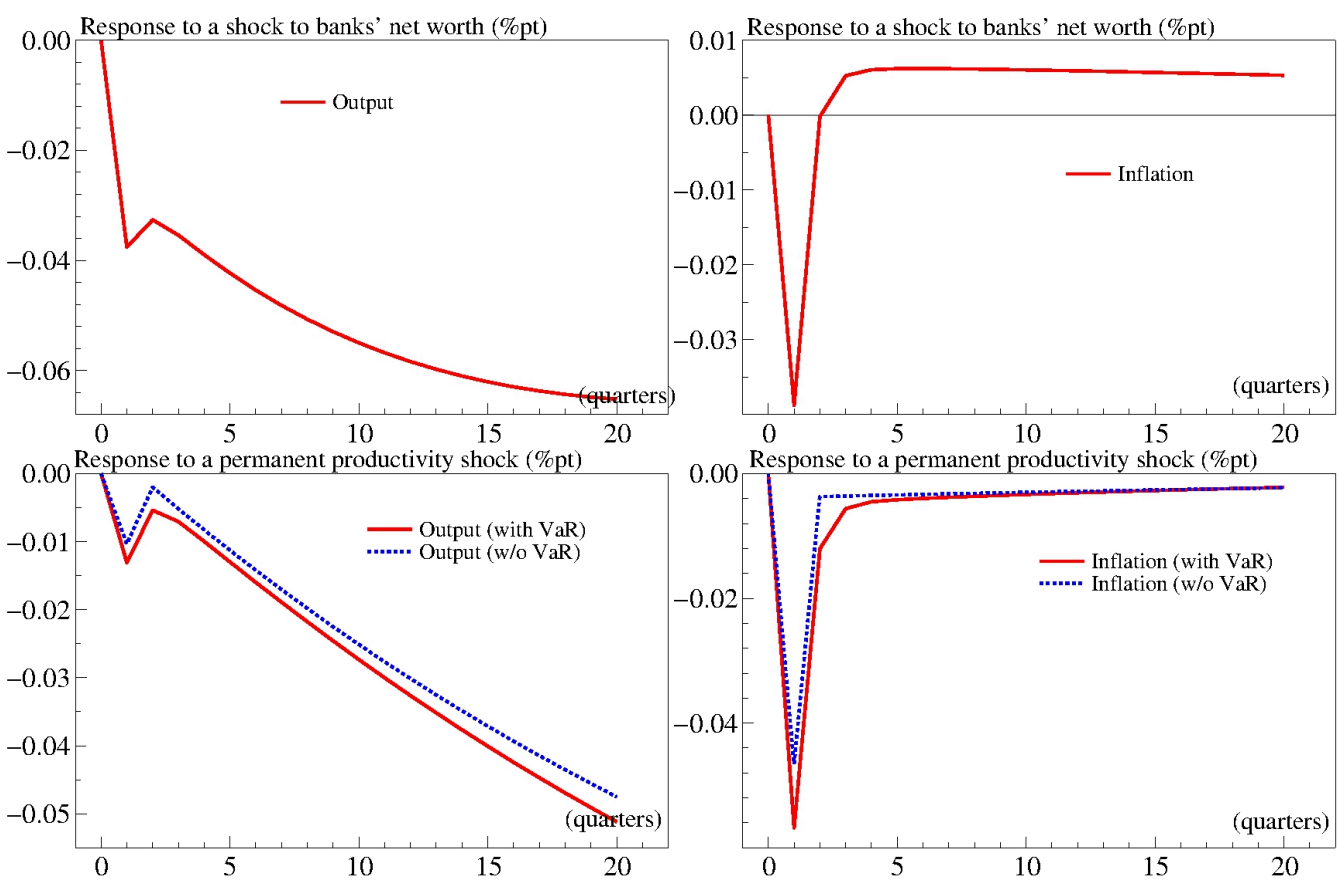
Figure 9

Effect of supply shock from China
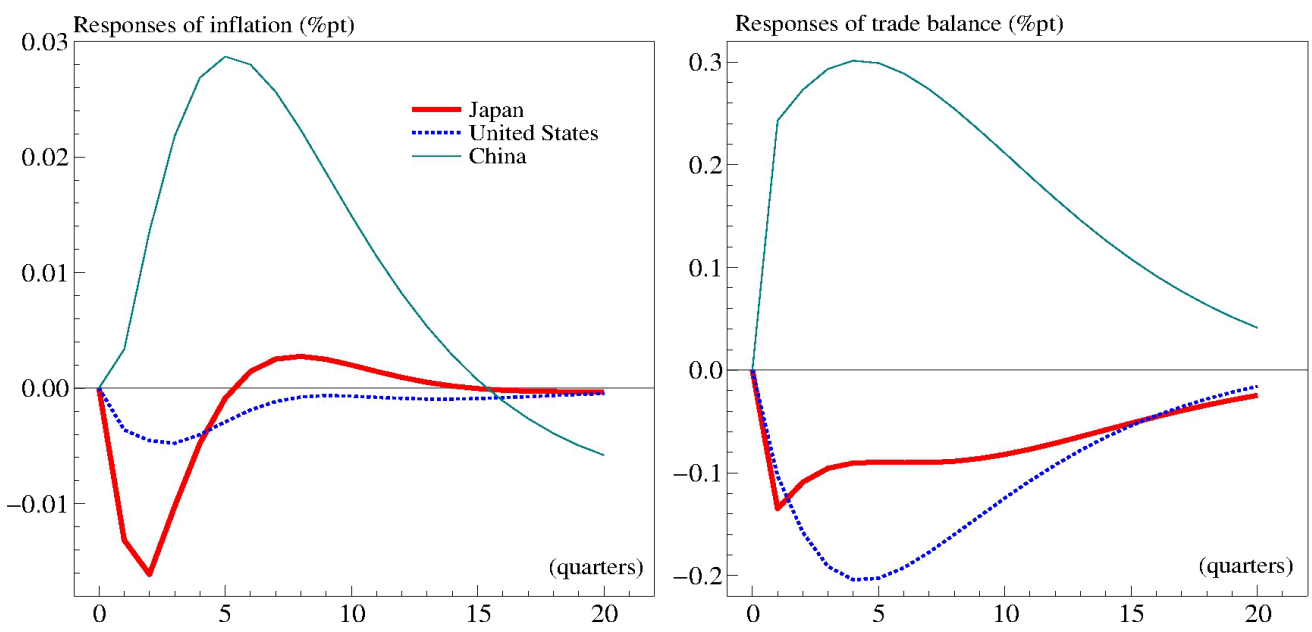

Table 1

Contribution of New Keynesian Phillips Curve variables (annual average, \%)

\section{\begin{tabular}{|l|l|l|l|l|}
\hline $1987-1990$ & $1990-1995$ & $1996-2000$ & $2001-2005$ & $2006-2009$ \\
\hline
\end{tabular}}

\begin{tabular}{|l|l|l|l|l|l|}
\hline CPI & 1.4 & 1.3 & 0.0 & -0.4 & 0.0 \\
\hline
\end{tabular}

Contributions to CPI

\begin{tabular}{|l|l|l|l|l|l|}
\hline Own lag & 0.5 & 0.4 & 0.0 & -0.1 & 0.0 \\
\hline $\begin{array}{l}\text { Trend } \\
\text { inflation }\end{array}$ & 1.5 & 1.2 & 0.7 & 0.6 & 0.9 \\
\hline
\end{tabular}

\begin{tabular}{|l|c|c|c|c|c|}
\hline $\begin{array}{l}\text { The output } \\
\text { gap }\end{array}$ & 0.6 & 0.1 & -0.3 & -0.4 & -0.3 \\
\hline Others & -1.2 & -0.4 & -0.4 & -0.6 & -0.6 \\
\hline
\end{tabular}


Table 2

\section{List of hypotheses}

\begin{tabular}{|c|c|}
\hline Inflation expectations & $\begin{array}{l}\text { - } \quad \text { Liquidity trap due to negative inflation expectations. } \\
\text { - } \quad \text { CB lowered the target. } \\
\text { - } \quad \text { PB communication problem. } \\
\text { Perception by the public that the prices in Japan were in } \\
\text { general too high. }\end{array}$ \\
\hline The output gap & $\begin{array}{ll}\text { - } & \text { Bad luck. } \\
\text { - } & \text { Liquidity trap due to negative growth expectations. } \\
\text { - } & \text { Permanent negative productivity shock. } \\
\text { - } & \text { Banks' risk aversion. }\end{array}$ \\
\hline Other factors & $\begin{array}{l}\text { - } \quad \text { Expectations for yen's appreciation. } \\
\text { - } \quad \text { Productivity shock in EMEs. }\end{array}$ \\
\hline
\end{tabular}




\section{References}

Adrian, T. and H. S. Shin (2010): "Financial Intermediaries and Monetary Economics," in Handbook of Monetary Economics, 1st edition, ed. by B. M. Friedman and M. Woodford, Elsevier, vol. 3, chap. 12, 601-650.

Aoki, K. and N. Sudo (2012): "Asset Portfolio Choice of Banks and Inflation Dynamics," Paper presented at the conference on Price Developments in Japan and Their Backgrounds: Experiences Since the 1990s, November 24, 2011, Bank of Japan, forthcoming in English as a Bank of Japan Working Paper (No. 12-J-4 in Japanese).

Krugman, P. R. (1998): “It's Baaack: Japan's Slump and the Return of the Liquidity Trap," Brookings Papers on Economic Activity, 137-205.

Laubach, T. and J. C. Williams (2003): "Measuring the Natural Rate of Interest," Review of Economics and Statistics, 85, 1063-1070.

Nishizaki, K, T Sekine and Y Ueno (2012): "Chronic deflation in Japan", Bank of Japan Working Paper Series, (forthcoming), No.12-E-6, Bank of Japan.

Saito, M., T. Fueki, I. Fukunaga, and S. Yoneyama (2012): "Structural Problems and Price Dynamics in Japan," Paper presented at the conference on Price Developments in Japan and Their Backgrounds: Experiences Since the 1990s, November 24, 2011, Bank of Japan Working Paper Series, No. 12-J-2, Bank of Japan, in Japanese.

Watanabe, T. (2012): "Long-Lasting Deflation under the Zero Interest Rate Environment," Paper presented at the conference on Price Developments in Japan and Their Backgrounds: Experiences Since the 1990s, November 24, 2011, Bank of Japan Working Paper Series, No. 12-J-3, Bank of Japan, in Japanese. 